Article

\title{
Comparison as a Provisional Activity
}

\author{
Nikolas O. Hoel $1 \mathrm{D}$ \\ Department of History, Northeastern Illinois University, Chicago, IL 60625, USA; n-hoel@neiu.edu
}

Received: 17 December 2019; Accepted: 3 January 2020; Published: 8 January 2020

\begin{abstract}
The careers of many scholars in various disciplines have been focused on the study of hagiography, including that of the author. Yet, as those scholars have uncovered new knowledge and employed new interpretations of the materials at hand, the very notions of "hagiography" and "hagiology" have become deeply problematized. The issues become more complex as multiple religious traditions are examined. The scholarly work that forms the basis of the essays in this volume has explored the effects of taking a comparative and collaborative approach to "hagiography". This piece responds to the core essays by showing first how personal the study of such sources and act of comparison can be, and then exploring how knowledge changes through the processes of comparison and collaboration. In the end, this response argues that comparison is by its very nature a provisional activity in that the knowledge it creates constantly changes as comparative methods and theories are re-applied again and again over time. This process is only aided by collaborative efforts which make the act of comparison even more effective and productive.
\end{abstract}

Keywords: collaborative scholarship; comparative method; comparative religions; hagiography; hagiology; religious studies; sacred biography; sainthood; theory and method in religious studies

No man ever steps in the same river twice, for it's not the same river and he's not the same man.

-Heraclites

Heraclites may be a strange place to start the discussion of comparison, and we will get back to him in a little while. Seemingly more germane, I think, is the fact that many scholars come to the idea and methods of comparison from strange places. For me, comparison started with a Gibbon-esque moment. Edward Gibbon claimed that he conceived of writing The Decline and Fall of the Roman Empire as he sat in Rome, writing that the idea came to him almost as a revelation. I had a similar experience, as a young graduate student pursuing my MA at the University of Colorado-Boulder, I stumbled across a Buddhist text which seemed very similar to the Latin saints' lives I had been studying. The book, which was entitled The Great Tang Dynasty Record of the Western Regions, contained the story of the eminent monk Xuanzang's pilgrimage to India from China in the seventh century (Li 1996). The wheels began to turn as I began to think that what I thought of as "hagiographic" texts might exist in multiple traditions and during many time periods. As I looked at the mountains that surrounded the campus, I came up with the idea that would become my dissertation. I compared Latin, Byzantine Greek, and Tang Chinese Buddhist vitae or their equivalent from the seventh through ninth century. My thinking about the topic was in its formative state and I have since become very aware of the problematic nature of calling the texts written about venerated individuals in non-Christian contexts "hagiography".

At the time, I thought I was the only one doing this work, and there were very few of us that were. Thankfully that number has been increasing over the last decade or so, which lead the pre-conference workshops on comparative hagiology that have taken place at the American Academy of Religion 
Annual Meeting the last few years. Many scholars seem to acknowledge the importance of comparison in the fields of history and religious studies. Chris Wickham has even gone so far as to call it essential (Wickham 2009). For Wickham, although there are challenges to employing comparison, by using it we can avoid solipsism, which prevents a single culture or tradition from becoming seen as normative. Yet the challenges to doing comparative work make the enterprise of comparing "hagiographies" across cultures daunting, if for no other reason than there is a lack of a universal vocabulary across cultures (Keune 2019) and the risk of decontextualization, essentialization and generalization clearly exists (Freiberger 2018).

The papers in this special issue are part of an effort to explore what "comparison" and "hagiology" are. They also serve to conceptualize what "comparative hagiology" is. At the AAR workshop in 2018, where the five core papers were originally discussed, I had the fortune to be a part of the group that discussed the one written by Jon Keune. The foundations he set for the discussion were beyond solid and we were off and running almost immediately. Most of that discussion, which centered on the issue of key terms, is reflected in Keune's paper in this volume. We talked about translation and metalinguistics. The group tried to grapple with the difference between "hagiology" and "hagiography". Then, a thought came to me and I wrote down in my notes a simple phrase: "any comparison is provisional".

Just as Wickham believes that comparison is essential, he also claims that it is hard (Wickham 2009). This, I believe, is where method comes into play, because, as Freiberger has argued, one must discuss what is problematic about comparison in both theoretical and methodological terms (Freiberger 2018). The method I used in my dissertation is that of Jonathan Z. Smith. In many ways reading Smith introduced me to the excitement of comparison and to its potential as a tool for furthering scholarly knowledge. He remarked that "comparison provides the means by which we 're-vision' phenomena as our data in order to solve our theoretical problems" (Smith 1990, p. 52). I was attracted to the concept that to Smith comparison is an active, playful exercise, one that deconstructs and reconstitutes (Smith 1990). The thought that a method could be "playful" appealed to me, who had gone to graduate school with the excitement of being able to play with ideas in the company of others who cared about them. The ideas were all well and good, but by what method was I to play with them? Smith provided that answer as well. I was introduced to his method in an essay entitled "The Bible and Religion," which I found in Relating Religion (Smith 2004). The essay was originally published in 2000. Smith's method consisted of four parts: description, comparison, re-description and rectification. Although Smith's method has been expounded upon by scholars such as Burton Mack (Mack 1996) and Oliver Freiberger (Freiberger 2018), the idea behind it has proven very useful. I employed this method, and an example of how I used it may be useful in understanding its potential. I looked at asceticism in multiple traditions. I described the rejection of certain foods and sex as a model for behavior in "hagiographies" produced in the Latin West, Greek Byzantium, and Tang Buddhist China in the seventh through ninth century. When I compared the behaviors of venerated persons in those traditions, they seemed to be doing very similar things. Yet, I looked deeper and re-described the actions of Buddhists, in particular those individuals who participated in self-immolation. In the sources that I considered, there are no examples of Christians who set themselves on fire. When I rectified this difference, I argued that Buddhists could set themselves on fire and Christians could not because of different theologies of the body: to Buddhists, the body did not exist, whereas to Christians the body was the image of God and thus ought not be destroyed by the human. In some ways, this conclusion was an example of essentializing the traditions, and I have come to realize in the time since writing the dissertation the problematic nature of this generalization.

For my dissertation, the method worked. Yet, in and of itself, it lends itself to adaptation. The knowledge the method produces is provisional, in that the knowledge changes as more studies are done. The more re-description one does, the finer the tuning of the ideas becomes. As more sources are considered, and hence the more data collected, the more rectification is needed. The results of comparison are thus provisional because further comparison may well lead to differing interpretations 
of the past and of different traditions. Even the methods of comparison can be changed. For example, in this special issue, Todd French describes the method of comparison used by the members of a session at the 2018 American Academic of Religion conference, which adapted previously established methods to create a better understanding of the phenomena the panelists wished to discuss (French 2019). In essence, French is describing one possible set of best practices in comparative studies of religion, yet he describes it as a "nascent attempt at best practices" (French 2019). These methods will most likely be supplanted as new ways of comparing texts and phenomena are determined to work better. Further as methods change, knowledge too will be refined.

The issue of language plays into the provisionality of comparison as well. Every paper in this special issue, in one way or another, deals with the issue of language and each author hints at the discomfort with the idea that the terms which described phenomena in one tradition could or should be used to describe those in another. In other words, at a fundamental level, does the word "saint" as conceived in the Christian tradition, reflect any lived experience in Hinduism, Buddhism, Islam, or any other tradition? The issue of language is Jon Keune's main focus here. He states that he agrees with Thomas Tweed that stipulative definitions are important but thinks that they should be applied at the end of the research process and not at the beginning (Keune 2019). He works to better define the difference between "hagiography" and "hagiology". David DiValerio notes the concern in the core essays with arriving at a precise definition of "hagiography" and argues that the lack of a shared vocabulary to describe the formal features of hagiographic texts is hindering our ability to study them (DiValerio 2019). Barbara Zimbalist, in her response here, notes that the authors of the core essays do not in all cases even agree on what constitutes the genre of "hagiography" or if it is a "genre" at all (Zimbalist 2019). The issue is complicated by Kevin Guilfoy who examines whether any of the terms we use and the concepts they represent can be translated from tradition to tradition or across time and space (Guilfoy forthcoming). As an outsider to the study of "comparative hagiology," he worries whether the enterprise is even possible because the concepts we are examining are socially constructed and historically situated, hence possibly within an epistemic tradition (Guilfoy forthcoming). We should certainly heed this warning, consider its implications, but not necessarily be dissuaded by it. Understanding how we use the terminology of our own fields and then working to collaborate to see how our colleagues understand their words will facilitate comparison and understanding in the end; a point Guilfoy seems to see as possible by the end of his essay. Thus, as a result of the work of all the authors here, language becomes problematized, yet at the same time remains critical to the enterprise of comparison.

I believe that however terms end up being defined, language itself is a critical piece of the provisional nature of comparison. Language is in constant flux; it changes regularly and irregularly at the same time. Language is in and of itself provisional and since it is used to describe phenomena, the descriptions are provisional as well. For example, in his essay in this volume, Massimo Rondolino proposes a new working definition of "hagiography" (Rondolino 2019). Three things are worth noting. First, his definition is the result of years of study and thought, and reflects a change, even if subtle, from the way he thought about "hagiography" while he was writing his book on the comparative study of hagiographical sources (Rondolino 2017). Second, he describes it as a working definition, implying the he thinks it is not static and needs redefining. Finally, his definition is already being considered by other authors in this volume (DiValerio 2019; Guilfoy forthcoming; Keune 2019). These three factors point to the reality that definitions are a work in progress, subject to change, and by nature provisional. As the language used to define categories of analysis change, so too does the understanding of them. This is particularly true in the case of comparison, which Freiberger has posited is a second-order method, which relies on first-order methods such as language analysis (Freiberger 2018). Thus, the effect of language on comparison is that as scholars further define terms and explore the intricacies of words and how they are used, comparison will be further clarified, and knowledge will be advanced. Keune's concluding sentence in this volume may well reinforce my thinking here as he suggests that "the real problem is not that the scope of comparison is too broad, but that the definitions of religion and saints 
are too small" (Keune 2019). When we continue to develop our understanding of what a "saint" is or is not, our comparisons have the potential to be deeper and more meaningful. Guilfoy, of course, problematizes this idea as he rightly points out that the term "saint" carries much cultural created value for Christians (Guilfoy forthcoming). Yet, even if the terms, like "saint," are not translatable across traditions, phenomena and discourses can be compared to create a more appropriate vocabulary and as a result further knowledge. Thus, as language changes, the fruits of comparison will change as further evidence that comparison is indeed provisional.

What then is the role of collaboration in the effort of comparison? If "comparative hagiology" is worthwhile, what is the best way to do it? The answer, for me, is that we continue to collaborate. While most of us will continue to produce single-author studies, we should also continue to work together. Collaboration in its purest form is the activity of bringing together many people with many ideas. Coming together as scholars has the potential to have value on a greater level. Scott Harrower remarks in the volume that comparison helps with our own individual self-reflection, it may also be a virtue-based approach, which introduces an element of social justice to what we are doing in this collaborative project (Harrower 2019). Harrower's suggestions surrounding the possible greater meaning of our work is certainly worth further exploration. In the immediate, although perhaps related, when new ideas are presented and considered, phenomena can be viewed in different ways. In essence, re-description occurs. Collaboration facilitates re-description. Re-description leads to new ways of reconciling diverse information and leads to new understanding of religious behavior, models, and belief. The mere act of working together increases the chances that new understandings will be achieved. In the end, we, as scholars, attempt to increase collective knowledge and memory. Further, by collaborating we can play with ideas that are otherwise unavailable, we walk along the path that would have been otherwise unavailable but is lined with, at least for me, excitement, intellectual questioning, and joy. It can be fun. The path may well be endless because it, like the fruits of comparison, are provisional. Knowledge and understanding will change as we work together.

What I argue here is that comparison is truly provisional. Through comparison, Massimo Rondolino has furthered the understanding of St. Francis and Milarepa (Rondolino 2017). In this volume, Sara Ritchey has argued that "'comparative hagiology' offers a method of productively destabilizing the assumptions and expectations that we, scholars working within specific intellectual, geographic, or confessional traditions, bring to our sources. This destabilization has the potential to make meaning across differences and, in the process, to generate new insights and understandings in our own areas of specialization" (Ritchey 2019). Through comparison, Jon Keune envision a broader and more inclusive field than exists today (Keune 2019). In the end, what we know about "hagiography" or "hagiology" today has the potential to be vastly different from what we will know in the future because of comparison. That comparison will be facilitated through collaborative efforts because more information will be available as each individual brings their knowledge to the collective table. Knowledge and understanding will change, and that is what I mean by provisional; comparison is only what it is at a specific moment: this one. At this point, I will come full circle, or perhaps more appropriately, down the river. Like Heraclites' river, knowledge is never the same as it is always moving. Comparison, then, as the current to the river's water, is that force that keeps knowledge in constant flux.

Funding: This research received no external funding.

Acknowledgments: Here I want to articulate my gratitude to Leonora Neville, my advisor at the University of Wisconsin-Madison, who encouraged me to write a very unorthodox dissertation and pushed me along even when it was not entirely certain it would yield fruitful results.

Conflicts of Interest: The author declares no conflict of interest. 


\section{List of Contributions}

DiValerio, David. 2019. A Preliminary Controlled Vocabulary for the Description of Hagiographic Texts. Religions 10: 585. doi:10.3390/rel10100585.

French, Todd. 2019. Saints across Traditions and Time Periods: Methods for Increasing Range and Reading in Comparative Frameworks. Religions 10: 577. doi:10.3390/rel10100577.

Guilfoy, Kevin. Forthcoming. Is Comparison Based on Translatable Formal Concepts? Religions.

Harrower, Scott. 2019. The Ethics of doing Comparative Hagiology. Religions 10: 660. doi:10.3390/rel10120660

Keune, Jon. 2019. Comparative vs. Hagiology. Two Variant Approaches to the Field. Religions 10: 575. doi:10.3390/rel10100575.

Ritchey, Sara. 2019. Dialogue and Destabilization: An Index for Comparative Global Exemplarity. Religions 10: 569. doi:10.3390/rel10100569

Rondolino, Massimo A. 2019. Some Foundational Considerations on Taxonomy: A Case for Hagiography. Religions 10: 538. doi:10.3390/rel10100538

Zimbalist, Barbara. 2019. Comparative Hagiology and/as Manuscript Studies: Method and Materiality. Religions 10: 604. doi:10.3390/rel10110604

\section{References}

Freiberger, Oliver. 2018. Elements of Comparative Methodology in the Study of Religion. Religions 9: 38. [CrossRef] Li, Rongxi. 1996. The Great Tang Dynasty Record of the Western Regions. BDK English Tripițaka, 79. Berkeley: Numata Center for Buddhist Translation and Research.

Mack, Burton. 1996. On Redescribing Christian Origins. Method and Theory in the Study of Religions 8: $247-69$. [CrossRef]

Rondolino, Massimo A. 2017. Cross-Cultural Perspectives on Hagiographical Strategies: A Comparative Study of the Standard Lives of St. Francis and Milarepa. Milton: Taylor and Francis.

Smith, Jonathan Z. 1990. Drudgery Divine: On the Comparison of Early Christianities and the Religions of Late Antiquity. Chicago: University of Chicago Press.

Smith, Jonathan Z. 2004. "Bible and Religion". In Relating Religion: Essays in the Study of Religion. Chicago: University of Chicago, pp. 197-214.

Wickham, Chris. 2009. Problems in Doing Comparative History. In Challenging the Boundaries of Medieval History: The Legacy of Timothy Reuter. Edited by Patricia Skinner. Tourhout: Brepolis, pp. 5-28. 